\title{
APPLICATION METHOD OF ANTIMICROBIAL SUB- STANCES FOR THE CONTROL OF SCHIZOPHYLLUM COMMUNE FR. CAUSING BROWN GERM AND SEED ROT OF OIL PALM
}

\author{
ANTARIO DIKIN ${ }^{1 *}$, KAMARUZAMAN SIJAM ${ }^{2}$ \\ AND IDRIS ABU SEMAN ${ }^{3}$ \\ ${ }^{1}$ Agricultural Quarantine Agency of Indonesia, Jakarta, Indonesia \\ ${ }^{2}$ Department of Plant Protection, Faculty of Agriculture, \\ Universiti Putra Malaysia, Selangor D.E, Malaysia \\ ${ }^{3}$ Plant Pathology and Weed Science Group, Biological Research Division Malaysian Palm \\ Oil Board, Selangor, D.E. Malaysia
}

\begin{abstract}
Biological seed treatment promotes to save the environment from toxic chemicals in the agricultural practices. Schizophyllum commune is one of the important seedborne pathogenic fungi causing brown germ and seed rot of oil palm which required effective and efficient treatment based on environmental friendly approaches. Anti-microbial substances are extracted from antagonistic bacteria of $B$. multivorans and $M$. testaceum after mass production in the liquid media. Application method of anti-microbial substances for the control of Schizophylllum commune was done by seed dipping for 30 minutes and vacuum infiltration at $400 \mathrm{~mm} \mathrm{Hg}$. vac. for $2 \mathrm{~min}$. in supernatant of anti-microbial substances diluted in sterilized distilled water with concentration ratio of 1:4. Application method using anti-microbial substances from antagonistic bacteria inhibited the growth of pathogenic fungus, enhanced seed germination, and without causing any abnormal growth of oil palm seedlings.
\end{abstract}

Key words : anti-microbial substances, seed treatment Schizophyllum commune Fr.

\section{INTRODUCTION}

Seed treatment as part of integrated pest management practically minimizes the infection of any plant pathogens associated with seeds. The application of seed treatment can be used as preventive and curative method against plant pathogens. Pre-treatment is normally applied to protect the seeds from soil-borne pathogens and to control seedborne pathogens. Schizophyllum commune Fr. causes brown germ and seed rot of oil

$\overline{\text { *Corresponding author : antario_dikin@yahoo.com }}$ 
palm. Heavy infection of the pathogen decreased seed germination of oil palm about 60\% (Dikin et al. 2003).

Fifty two antagonistic bacterial isolates from oil palm plantation in Peninsular Malaysia were potential agents for suppressing the growth of $S$. commune. Of the 52 isolates which produced anti-microbial substances Burkholderia cepacia $\mathrm{Rb} 47, B$. multivoras RU50 and Microbacterium testaceum RU7 inhibited the growth of S. commune (Dikin et al. 2006).

Formulation of active compounds in the bio-pesticide such as pyrrolnitrin from Pseudomonas cepacia was developed by micro-encapsulation using gluten and casein. The micro-encapsulations protected active agents which are sensitive to direct light exposure and extreme temperature (Yu and Lee 1997).

Bacillus subtillis is an antagonistic bacteria of S. commune formulated as biopesticide in dry powder form. Dry powder as the carrier of bacterial spores in the slurry is to protect seeds from the infection of Rhizoctonia solani, Fusarium spp., Alternaria spp., and Aspergillus spp. (Fravel et al.1998; Desai et al. 2002). Potential supernatant of anti-microbial substances from B. multivorans RU50 and $M$. testaceum RU7 suppressed the growth of S. commune in vitro. Meanwhile, in vivo application for the control of brown germ and seed rot diseases of oil palm requires further studies.

The objectives of the study were to determine the anti-microbial substances from B. multivorans RU50 and M. testaceum RU7 to control brown germ and seed rot diseases and to evaluate their potential preventive measures of oil palm seeds.

\section{MATERIALS AND METHODS}

\section{Antimicrobial substance}

One loop-full of B. multivorans RU50 and M. testaceum RU7 isolates were inoculated to 1 liter of sterilized liquid media ( $10 \mathrm{~g}$ of neo peptone, $10 \mathrm{~g}$ of lactose and $10 \mathrm{~g}$ of peptone, $10 \mathrm{~g}$ of maltose, respectively, for each species of bacteria). Liquid media containing the cell of each bacterial isolate were fermented in electric rotator (New Brunswick Scientific G-25KC) at $125 \mathrm{rpm}$ for 5 days, and then added with 50 $\mathrm{ml}$ of absolute methanol. Supernatant from fermented liquid media was separated using centrifugation and evaporated using Buchi rotavopor R-200 at $45^{\circ} \mathrm{C}$ to reach $100 \mathrm{ml}$ (Dikin et al. 2006).

\section{Effect of anti-microbial substances on non-germinating oil palm seeds inoculated with S. commune}

Twenty five pre-heated oil palm seeds were artificially inoculated with $S$. commune by placing the seeds onto $S$. commune cultural plates, and then incubated in polythene bags for 7 days at room temperature for mycelial colonization. Inoculated seeds were 
Application method of antimicrobial substances - A. Dikin et al.

treated with anti-microbial substances from mixing supernatant of B. multivorans RU50 and $M$. testaceum RU7. The ratios for treatment concentration of seed dipping were 1 :2 (R2), 1:4 (R4), $1: 6$ (R6), and as control dipped into distilled water (Sc-dip) for 30 minutes. Other treatments of inoculated seeds were infiltrated in the anti-microbial substances of various concentrations namely 1:2 (V2), 1:4 (V4), 1:6 (V6) and as control the seeds were infiltrated into distilled water at $400 \mathrm{~mm} \mathrm{Hg}$ vac. for $2 \mathrm{~min}$. The preheated seeds non inoculated with $S$. commune were used as negative control. Treated non germinating seeds and the control were air dried in laminar chamber, and then incubated in polythene bags at $26 \pm 2^{\circ} \mathrm{C}$. Observation of seed germination was carried out at 14,21,28 days interval. Four replicates were made for each treatment including control (Dikin et al. 2003).

\section{Effect of anti-microbial substances on the fungal colonization}

Ten pre-heated oil palm seeds were treated with the supernatant of anti-microbial substances by dipping, vacuum infiltration, and seed coating. As control, the seeds were not treated with anti-microbial substances. As comparison, the seeds were dipped in a synthetic fungicide, $0.2 \%$ of mancozeb. Dipping treatment was conducted by soaking oil palm seeds in diluted anti-microbial substances 1:4 (R4) for 30 minutes. Vacuum treatment was conducted by soaking and infiltration the seeds in diluted anti-microbial substances with ratio of 1:4 (V4) at $400 \mathrm{~mm} \mathrm{Hg}$ Vac. for $2 \mathrm{~min}$. Seed coating was conducted by coating oil palm seeds with freeze-drying of anti-microbial substances in talc. The rate of concentration between talc and anti-microbial supernatant suspension was 1:1. Seeds treated with anti-microbial supernatant were mixed with the talc powder in a polythene bag and shaken until the powder covered the whole seeds. The seeds were air dried, and then placed on the culture plate of 7-day-old S. commune. Plates were incubated at room temperature in polythene bags. The colonized seeds were recorded for each treatment. Five replicates were made for each treatment including control.

\section{Comparison of various pre-treatments of artificial inoculation of oil palm seeds on seed germination}

Twenty five pre-heated oil palm seeds were treated with supernatant of antimicrobial substances by dipping (R4), vacuum (V4), seed coating by freeze dry solidification of anti-microbial substances in talc with concentration ratio of $1: 1$, dipping oil palm seeds in the suspension of peptone maltose, neo peptone lactose for 30 minutes. as negative control. As comparison oil palm seeds were dipped in the synthetic fungicide of $0.2 \%$ mancozeb. For dipping treatment seeds were shaken in diluted antimicrobial substances with concentration of 1 part of supernatant of anti-microbial substances diluted with 4 parts of distilled water (R4) for 30 minutes. For vacuum treatment the seeds were soaked and vacuumed in diluted anti-microbial substances with concentration of 1 part of supernatant of anti-microbial substances diluted with 4 parts of distilled water (V4) at $400 \mathrm{~mm} \mathrm{Hg}$. vac. for $2 \mathrm{~min}$. Treated seeds were placed 
on cultural plates of 7-day-old S. commune and then incubated for 7 days in polythene bags at room temperature. Then the seeds were collected and placed in a polythene bag for percentage of germination. Seeds were incubated for 28 days at room temperature and the germination recorded. Three replicates were made for each treatment.

\section{Effect of pre-treated artificial inoculation of oil palm seeds on the growth of seedling}

A number of 10 germinated oil palm seeds from each treatment including control i.e. the protective treatment including seed dipping in diluted anti-microbial substances with ratio of 1:4 (R4) in distilled water, vacuum seed in diluted anti-microbial substances with ratio of $1: 4$ (V4), seed coating by freeze-dry solidification of antimicrobial substances in talc with ratio of $1: 1$, seed dipping in mancozeb, inoculated seeds treated with liquid solution of neopeptone, peptone, maltose, lactose as negative control and healthy seeds as positive control was sown in plastic pots $(29 \times 39 \times 10 \mathrm{~cm})$. Seedling growth was maintained by watering and measuring the height of seedlings every week and the dry weight of seedlings were recorded at 12 weeks. Three replicates were made for each treatment (Dikin et al. 2003).

\section{RESULTS AND DISCUSSION}

The mixed supernatant of antimicrobial substances from $B$. multivorans and $M$. testaceum were solidified in talc and kaolin as carrier by dry air heating and freeze -drying. Both solidified anti-microbial substances in talc and kaolin affected the diametric clear zone of $S$. commune. Dissolved freeze-dried anti-microbial substances in talc with distilled water 1:1 showed diametric clear zone highest formation of $21 \mathrm{~mm}$, followed by freeze dried kaolin, air heating dried talc, and air heating dried kaolin with the diametric clear zone of $S$. commune i.e. $17.3 \mathrm{~mm}, 15.3 \mathrm{~mm}$ and 14.6 $\mathrm{mm}$ respectively. The formulation of anti-microbial substances in freeze-dried talc suppressed the growth of $S$. commune at dissolved ratio, 1:25, followed by freeze-dried kaolin. Both freeze-dried talc and kaolin showed diametric clear zone of $14 \mathrm{~mm}$ and $13.6 \mathrm{~mm}$, respectively. Meanwhile, the air heating of dried talc and kaolin dissolved in distilled water at ratio 1:10 suppressed the growth of $S$. commune (Table 1.). 
Application method of antimicrobial substances - A. Dikin et al.

Table 1: Clear zone diameter of S. commune against diluted anti-microbial substances in powder form

\begin{tabular}{|c|c|c|c|c|c|c|c|c|}
\hline \multirow{2}{*}{$\begin{array}{l}\text { Formulated } \\
\text { antimicrobial } \\
\text { substances }\end{array}$} & \multicolumn{7}{|c|}{$\begin{array}{l}\text { Diluted ratio (anti-microbial substance in powder form : } \\
\text { sterilized water) }^{\mathrm{a}}\end{array}$} & \multirow[t]{2}{*}{ Average } \\
\hline & $1: 1$ & $1: 5$ & $1: 10$ & $1: 15$ & $1: 20$ & $1: 25$ & $1: 30$ & \\
\hline $\begin{array}{l}\text { Freeze dry of } \\
\text { kaolin }\end{array}$ & $17.3 \mathrm{aB}$ & $17 \mathrm{aB}$ & $16 \mathrm{bB}$ & $15.3 \mathrm{cB}$ & $14.6 \mathrm{~dB}$ & $13.6 \mathrm{eB}$ & OfA & 13.4 \\
\hline Freeze dry of talc & $21 \mathrm{aA}$ & $20 \mathrm{bA}$ & $16.3 \mathrm{cA}$ & $15.6 \mathrm{dA}$ & $15 \mathrm{eA}$ & $14 \mathrm{fA}$ & $0 \mathrm{gA}$ & 14.5 \\
\hline $\begin{array}{l}\text { Dry air heating } \\
\text { of kaolin }\end{array}$ & $14.6 \mathrm{aD}$ & $14.3 \mathrm{aC}$ & $14.3 \mathrm{aC}$ & $\mathrm{ObC}$ & $\mathrm{ObC}$ & $\mathrm{ObC}$ & ObA & 6.1 \\
\hline $\begin{array}{l}\text { Dry air heating } \\
\text { of talc }\end{array}$ & $15.3 \mathrm{aC}$ & $13.3 \mathrm{bD}$ & $12.6 \mathrm{cD}$ & $0 \mathrm{dC}$ & $0 \mathrm{dC}$ & $0 \mathrm{dC}$ & $0 \mathrm{Da}$ & 5.8 \\
\hline Average & 17 & 16.1 & 14.8 & 7.7 & 7.4 & 6.9 & 0 & \\
\hline
\end{tabular}

Note:

${ }^{a}$ Average of three replications. Means followed by different small letters within row $\left(\mathrm{LSD}_{0.05}=0.3 \mathrm{~mm}\right)$ and different capital letters within column $\left(\mathrm{LSD}_{0.05}=0.2 \mathrm{~mm}\right)$ are significantly different.

Among the two carriers with two drying techniques, freeze-dried talc was the best formulation of anti-microbial substances of B. multivorans and $M$. testaceum. Dry air heating, freeze-dried talc and kaolin had different rigidity in grinding to obtain small size particles. It was easier to grind the solidified anti-microbial substances by freeze-drying technique than dry air heating.

\section{Effect of supernatant of antimicrobial substances on non-germinating oil palm seeds inoculated with $S$. commune}

Liquid form of supernatant of anti-microbial substances from B. multivorans and $M$. testaceum significantly suppressed the growth of $S$. commune in the oil palm seeds $(\mathrm{P}=0.05)$. The potential anti-microbial substances reduced the oil palm seed infection and enhanced the seed germination of oil palm. Seed treatment of oil palm by dipping and vacuum showed that both treatments affected $S$. commune infection in the seed. Seed germination of healthy oil palm seeds at 28 days after incubation was $95 \%$. Seed germination of artificial inoculated seeds dipped and vacuumed in distilled water was 17 and $56 \%$, respectively. Seed treatment with supernatant of anti-microbial substances significantly recovered seed germination. Dipping (R4) and vacuuming (V4) treatment with supernatant of anti-microbial substances reached germination of 94 and $93 \%$, respectively, and was not significantly different compared to healthy seeds i.e. $92 \%$ (Table 2). Seed treatment of oil palm with supernatant of anti-microbial substances suppressed fungal growth. Mycelia colonized the whole seed and penetrated up to the kernel through germ pores. Germ pores of seeds were blocked by compact mycelia and caused a failure in germination. The inhibition of mycelial growth of $S$. commune on 
the whole seeds using anti-microbial substances i.e. dipping and vacuum treatment induced seed germination. At the early stage, the germination plugs of the treated seeds release from germ pores; radicle and plumule gradually came out with soft tissue and white in colour.

Table 2. Percentage of seed germination of oil palm seeds after incubation

\begin{tabular}{cccc}
\hline \multirow{2}{*}{ Treatment*) } & \multicolumn{3}{c}{ Days of incubation } \\
\cline { 2 - 4 } Control Without Sc & 14 & 21 & 28 \\
Sc Vac & $92 \mathrm{a}$ & $92 \mathrm{a}$ & $95 \mathrm{a}$ \\
Sc Dip & $53 \mathrm{~d}$ & $56 \mathrm{e}$ & $56 \mathrm{f}$ \\
R2 & $16 \mathrm{f}$ & $16 \mathrm{f}$ & $17 \mathrm{~g}$ \\
R4 & $22 \mathrm{e}$ & $60 \mathrm{~d}$ & $78 \mathrm{e}$ \\
R6 & $70 \mathrm{c}$ & $82 \mathrm{c}$ & $94 \mathrm{ab}$ \\
V2 & $72 \mathrm{c}$ & $82 \mathrm{c}$ & $86 \mathrm{~d}$ \\
V4 & $72 \mathrm{c}$ & $88 \mathrm{~b}$ & $90 \mathrm{c}$ \\
V6 & $89 \mathrm{ab}$ & $92 \mathrm{a}$ & $93 \mathrm{ab}$ \\
\hline
\end{tabular}

Notes:

Average of four replications. Means within column with the same small letter are not significantly different at $\mathrm{P}=0.05$ according to Least Significant Different Test

*) R2 = dipping treatment with one part of supernatant anti-microbial substances and added two parts of distilled water

R4 = dipping treatment with one part of supernatant anti-microbial substances and added four parts of distilled water

R6 = dipping treatment with one part of supernatant anti-microbial substances and added six parts of distilled water

$\mathrm{V} 2$ = vacuum treatment with one part of supernatant anti-microbial substances and added two parts of distilled water

V4 = vacuum treatment with one part of supernatant anti-microbial substances and added four parts of distilled water

V6 = vacuum treatment with one part of supernatant anti-microbial substances and added 6 parts of distilled water

Control without $\mathrm{Sc}=$ healthy seeds (control)

$\mathrm{Sc}$ Vac $=$ vacuum treatment of artificial inoculated seeds in distilled water

ScDip = dipping treatment of artificial inoculated seeds in distilled water

\section{Comparison of various pre-treatments of artificial inoculation of oil palm seeds on seed germination}

Pre-treatment of seed using anti-microbial substances was able to protect the fungal growth and was reflected by the seed germination recovery. From the different pre-treatments in the application of anti-microbial substances as preventive measures, 
Application method of antimicrobial substances - A. Dikin et al.

28-day treatment after incubation showed that dipping and vacuum significantly increased the percentage of seed germination. Both dipping and vacuum pre-treatments increased the germination rate, compared to seeds without artificial inoculation. Both dipping and vacuum pre-treatments were also significantly different with the application of synthetic fungicide, mancozeb $(\mathrm{P}=0.05)$. Seed coating with freeze dry anti-microbial substances in talc was not significantly different with non-inoculated seeds and significantly different with artificial inoculated seeds treated with distilled water or liquid medium (neo peptone, lactose, peptone, maltose) as negative control (Table 3.).

Table 3: Percentage of seed germination of pre-treated seeds before artificial inoculation with $S$. commune*)

\begin{tabular}{cccc}
\hline & \multicolumn{3}{c}{ Days of incubation } \\
\cline { 2 - 4 } Pre-treatment & 14 & 21 & 28 \\
\hline Vacuum & $37 \mathrm{~b}$ & $72 \mathrm{a}$ & $84 \mathrm{a}$ \\
Dipping & $31 \mathrm{c}$ & $72 \mathrm{a}$ & $84 \mathrm{a}$ \\
Seed Coating & $25 \mathrm{~d}$ & $51 \mathrm{~b}$ & $80 \mathrm{~b}$ \\
Mancozeb & $26 \mathrm{~cd}$ & $51 \mathrm{~b}$ & $81 \mathrm{~b}$ \\
Without S. commune (positive control) & $73 \mathrm{a}$ & $76 \mathrm{a}$ & $81 \mathrm{~b}$ \\
Inoculated S. commune + water (negative & $11 \mathrm{e}$ & $12 \mathrm{c}$ & $33 \mathrm{c}$ \\
control) & & & \\
Inoculated S. commune + neopeptone lactose & $13 \mathrm{e}$ & $13 \mathrm{c}$ & $25 \mathrm{~d}$ \\
peptone maltose (negative control) & & & \\
\hline
\end{tabular}

Note : Average of four replications. Means followed by different small letters within column are significantly different (LSD P=0.05)

\section{Supernatant of anti-microbial substance as seed protector against infection of S. commune}

Supernatant of anti-microbial substances from B. multivorans and $M$. testaceum protected oil palm seeds from infection of $S$. commune (Figure 1.). The anti-microbial substances in the liquid form and solidified anti-microbial substances in talc significantly inhibited colonization of $S$. commune on all oil palm seeds. Vacuum pre-treatment of oil palm seeds significantly reduced the colonization of fungus up to $88 \%$, followed by seed coating with solidified anti-microbial substances in talc which reduced the colonization of fungus by $66 \%$ and dipping pre-treatment reduced the colonization of fungus by $16 \%$. The synthetic fungicide, mancozeb at $2 \mathrm{~g} / 1$ in distilled water did not protect the seeds from the colonization of $S$. commune (Table 4.). 

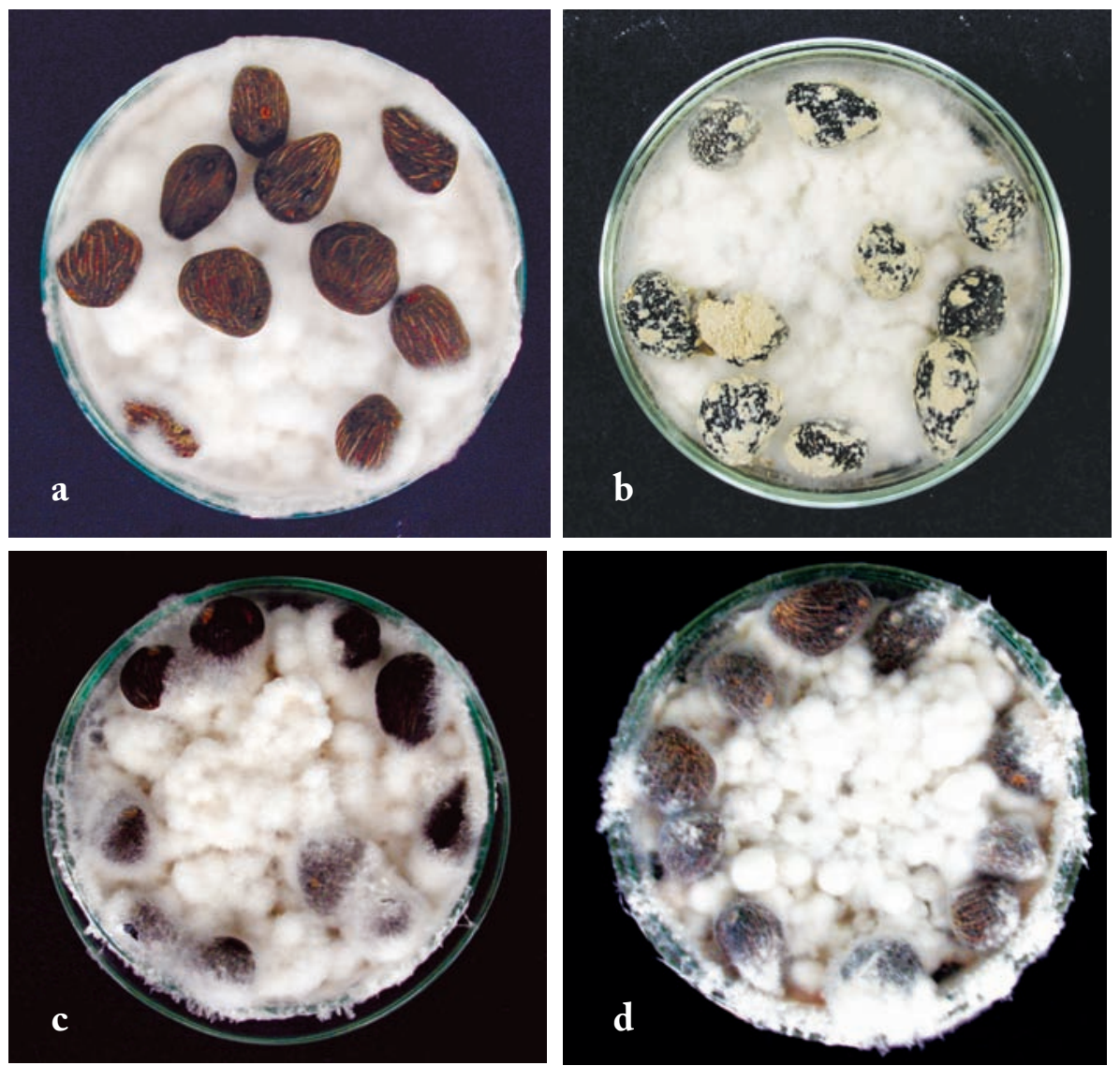

Figure 1: a. Oil palm seeds after vacuum pre-treatment with anti-microbial substances b. Seed coating with freeze-dry solidified anti-microbial substances in talc c. Dipping pre-treatment with anti-microbial substances

d. Seeds without anti-microbial substances as control

Table 4: $\quad$ Percentage of pre-treated oil palm seeds colonized by S. commune (\%)

\begin{tabular}{lc}
\hline \multicolumn{1}{c}{ Pre-treatment } & $\begin{array}{c}\text { Seed coloniza- } \\
\text { tion }(\%)^{*}\end{array}$ \\
\hline Dipping in anti-microbial substances with concentration 1:4 & $84 \mathrm{~b}$ \\
Vacuum in anti-microbial substance with dose 1:4 & $12 \mathrm{~d}$ \\
Seed Coating with solidified anti-microbial substances in talc & $34 \mathrm{c}$ \\
Mancozeb & $100 \mathrm{a}$ \\
Without anti-microbial substances (Control) & $100 \mathrm{a}$ \\
\hline
\end{tabular}

Note : Average of five replications. Means followed by different small letters within column are significantly different (LSD p $=0.05)$. 
Application method of antimicrobial substances - A. Dikin et al.

\section{Effect of pre-treated artificial inoculation of oil palm seeds on the growth of seedlings}

Seed treatment of artificially inoculated seeds with anti-microbial substances induced seed germination. Schizophyllum commune with its compact mycelia blocked the germ pores and was found to be the main cause of germination loss. When the radicle and plumule already emerged from seed, and the seed infection of $S$. commune took place, germinated seeds were still able to continue its growth. The anti-microbial substances showed impacts on suppressing the fungal growth during germination, and did not inhibit seedling growth. Seedling height from inoculated seeds and then treated with dipping in distilled water showed growth inhibition (Figure 2). Seedling height at 12 weeks old showed that all treatments of vacuumed and dipped in anti-microbial substances and non inoculation of $S$. commune were not significantly different. Mean dry weight of 12-week-old seedling treated with V2, V4, V6, R2, R4, R6, water dipping $(\mathrm{C}-\mathrm{Wt})$ and water vacuum (c-CV) were significantly different. Vacuum treatment (V2, V4) enhanced dry weight of seedling followed by others (Table 5).
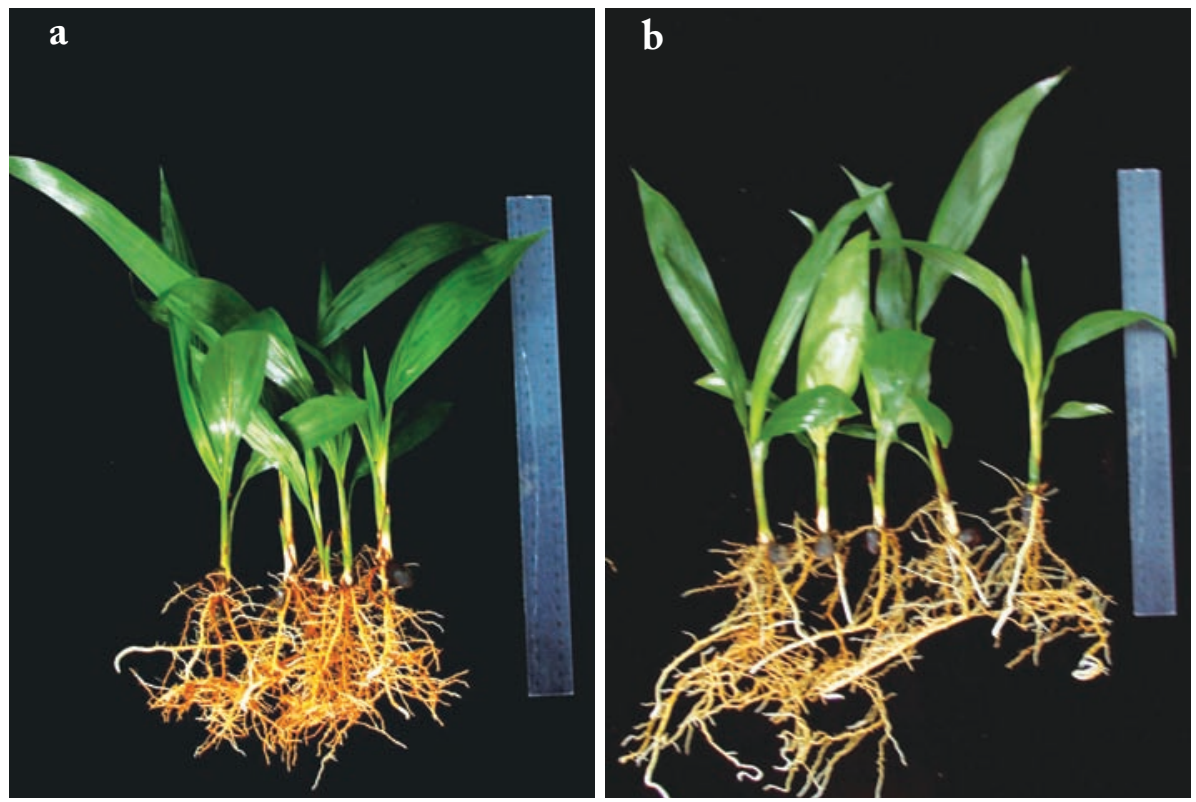

Figure 2. Oil palm seedlings from artificially inoculated seeds with S. commune

a. Without treatment with anti-microbial substances

b. Treated artificially with anti-microbial substances 
BIOTROPIA VOL.15 NO. 1, 2008

Table 5: Height of oil palm seedling from the treated germinating seeds $(\mathrm{cm})$

\begin{tabular}{cccccccccc}
\hline $\begin{array}{c}\text { Seed- } \\
\text { ling age } \\
\text { (week) }\end{array}$ & $\mathrm{C}-\mathrm{Wt}$ & $\mathrm{No}-\mathrm{Sc}$ & $\mathrm{V} 2$ & $\mathrm{~V} 4$ & $\mathrm{~V} 6$ & $\mathrm{R} 2$ & $\mathrm{R} 4$ & $\mathrm{R} 6$ & $\mathrm{C}-\mathrm{Vc}$ \\
\hline 6 & $13.7 \mathrm{~d}$ & $15.7 \mathrm{ab}$ & $15.3 \mathrm{ab}$ & $15.4 \mathrm{ab}$ & $15.1 \mathrm{bc}$ & $15.4 \mathrm{ab}$ & $16.3 \mathrm{a}$ & $14.9 \mathrm{bc}$ & $14.1 \mathrm{dc}$ \\
7 & $15.3 \mathrm{c}$ & $17.6 \mathrm{~b}$ & $18.4 \mathrm{ab}$ & $18.5 \mathrm{ab}$ & $17.8 \mathrm{ab}$ & $17.9 \mathrm{ab}$ & $19.3 \mathrm{a}$ & $18.5 \mathrm{ab}$ & $17.1 \mathrm{~b}$ \\
8 & $18.3 \mathrm{c}$ & $19.1 \mathrm{bc}$ & $19.1 \mathrm{bc}$ & $21 \mathrm{a}$ & $19.6 \mathrm{abc}$ & $20 \mathrm{abc}$ & $21.2 \mathrm{a}$ & $19.9 \mathrm{abc}$ & $20.1 \mathrm{ab}$ \\
9 & $19.7 \mathrm{c}$ & $20.1 \mathrm{bc}$ & $21.7 \mathrm{a}$ & $21.9 \mathrm{a}$ & $21 \mathrm{abc}$ & $21.3 \mathrm{ab}$ & $21.7 \mathrm{a}$ & $20.5 \mathrm{abc}$ & $20.9 \mathrm{abc}$ \\
10 & $19.7 \mathrm{~b}$ & $21.6 \mathrm{a}$ & $22.8 \mathrm{a}$ & $22.7 \mathrm{a}$ & $22.6 \mathrm{a}$ & $22.1 \mathrm{a}$ & $22.7 \mathrm{a}$ & $21.7 \mathrm{a}$ & $21.4 \mathrm{ab}$ \\
11 & $21.4 \mathrm{~d}$ & $23.8 \mathrm{ab}$ & $24.5 \mathrm{a}$ & $23.6 \mathrm{ab}$ & $23.8 \mathrm{ab}$ & $23.7 \mathrm{ab}$ & $23.2 \mathrm{bc}$ & $23.3 \mathrm{bc}$ & $22.5 \mathrm{c}$ \\
12 & $22.5 \mathrm{~b}$ & $24.6 \mathrm{a}$ & $25.8 \mathrm{a}$ & $26 \mathrm{a}$ & $25.6 \mathrm{a}$ & $25.1 \mathrm{a}$ & $25.8 \mathrm{a}$ & $25.7 \mathrm{a}$ & $24.9 \mathrm{a}$ \\
$\begin{array}{c}\text { Dry } \\
\text { Weight } \\
\text { (mg) }\end{array}$ & $1242 \mathrm{~b}$ & $1250 \mathrm{ab}$ & $1425 \mathrm{a}$ & $1431 \mathrm{a}$ & $1265 \mathrm{ab}$ & $1281 \mathrm{ab}$ & $1345 \mathrm{ab}$ & $1337 \mathrm{ab}$ & $1368 \mathrm{ab}$ \\
\hline
\end{tabular}

Note : Average of thirty replications. Means followed by different letters within the same row are significantly different (LSD P=0.05).

Formulation of supernatant of anti-microbial substances from B. multivorans and $M$. testaceum were solidified in the carrier of talc and kaolin which affected the MIC of ant-imicrobial substances against $S$. commune. The carrier of talc and kaolin as aggregate ingredients has the function to release and dissolve anti-microbial substances easily and faster in water without reduction of active compounds to suppress the growth of $S$. commune. Freeze-dry solidification of supernatant of anti-microbial substances was not easy to keep it in dry powder form. The freeze-dried powder of supernatant of anti-microbial substances is hygroscopic and trapped water from the air. After 24 hours in open air, the freeze-dried powder of anti-microbial substances becomes liquid. Talc and kaolin as the carriers of anti-microbial substances with concentration ratio of $1: 1$ formulated the anti-microbial substances to the powder form and act as bio-pesticide. The concentration ratio of anti-microbial substances in talc or kaolin was 1:1 and avoided water trapped by the formulated bio-pesticide from the air.

Dry technique of freeze-drying and dry air heating in the solidification of supernatant of anti-microbial substances in talc and kaolin had different values of minimum inhibitory concentration (MIC). Dry air heating of talc and kaolin at $60^{\circ} \mathrm{C}$ for 48 hours reduced the potential of anti-microbial substances to inhibit $S$. commune. Actually, the stability of ant-microbial substances from $B$. multivorans and $M$. testaceum against the temperature in the powder form was up to $60^{\circ} \mathrm{C}$ within 2 hours. Other limiting factors in dry air heating of solidified anti-microbial substances in talc and kaolin were hardening, difficult to grind and not easy to dissolve in water compared with freeze dry solidification of anti-microbial substances in talc and kaolin. Lower 
Application method of antimicrobial substances - A. Dikin et al.

value of MIC anti-microbial substances in talc and kaolin powder compared to the liquid form was due to reduction half of the active compounds and also the content of active compounds, such as phenazine, pyrrolnitrin and phenylpyrrol which was too small based on HPLC analysis. Synthetic fungicide such as Thiram with a dose of 2 $\mathrm{g} / 1$ is used for seed treatment of oil palm (Turner and Gillbanks 2003). Although, the ratio of concentration of this synthetic fungicide was relatively high, the potential of suppressing pathogenic fungus was still effective. The pre-treatment of oil palm seeds using formulated anti-microbial substances in liquid form was effective to control $S$. commune. Schizophyllum commune attacked oil palm seeds through direct contact between infected seeds and healthy seeds, and then the mycelia colonized the whole seed. Based on the dry weight of 12 -week-old seedlings, seed treatment of inoculated seeds with antimicrobial substances did not inhibit seedling growth. The liquid formulation protected the attack of $S$. commune by the colonizing oil palm seeds. Vacuum pre-treatment was more effective than dipping pre-treatment in the application of liquid formulation as protective measure. Vacuum pre-treatment quantitatively enhanced the absorption of anti-microbial substances by the oil palm seeds. Mean while, dipping pre-treatment showed that the anti-microbial substances covered the whole seeds, dry faster in the open air and less absorption of anti-microbial substances. The difference in absorption quantity of anti-microbial substances on both vacuum and dipping pre-treatment in the seeds is equal to different applications of the concentration of anti-microbial substances.

Effective dose in the application of liquid formulation was one part supernatant of anti-microbial substances from B. multivorans and $M$. testaceum dissolved into four parts of distilled water. However, for the application of freeze-dry solidified antimicrobial substances in talc it was equal to one gram dissolved in two $\mathrm{ml}$ of distilled water. This dose of powder formulation was able to suppress the fungal growth, but the application of seed pre-treatment caused less germinating seeds, due to the formulated talc in the wet powder to cover the whole seeds which strongly blocked the germ pores for the absorption of the required oxygen in respiration activity before and after germination.

Coating pre-heated seeds with solidified freeze dry anti-microbial substances in talc apparently protected the oil palm seeds from contaminant fungi for long period in store. Coating pre-heated seeds with synthetic fungicide is commonly used to protect oil palm seeds from contaminant fungi in the intercontinental trade. Slurry pre-treated seeds were washed with water to remove the fungicide on seed surface before germination process (Dikin et al. 1995).

Pre-treatment of seeds using supernatant anti-microbial substances from $B$. multivorans and $M$. testaceum controlled artificially inoculated seeds with $S$. commune. The recovery of seed germination of oil palm was due to treatment of supernatant antimicrobial substances. The effect of application of anti-microbial substances, as curative or preventive measure on seed germination and seedling growth showed no significant 
differences with healthy seeds. Based on the results, the application of anti-microbial substances for the control of $S$. commune confirmed that the supernatant anti-microbial substances from $B$. multivorans and $M$. testaceum contain at least 3 active compounds of pyrrolnitrin, phenylpyrrol and phenazine which did not cause negative effect on seedling growth. These active compounds were reported to inhibit fungal growth (Cartwright et al. 1995).

\section{CONCLUSIONS}

Supernatant of anti-microbial substances from B. multivorans and $M$. testaceum have been formulated in liquid form and freeze-dried talc form. Both formulations had different functions for the control of $S$. commune as preventive and curative measures. Formulated anti-microbial substances in liquid form and freeze dry solidification in talc had different values of minimum inhibitory concentration.

Application of the supernatant anti-microbial substances in liquid form for preventive and curative measures was conducted by seed dipping for 30 minutes and vacuum $400 \mathrm{~mm} \mathrm{Hg}$ vacuum for 2 minutes with ratio concentration of 1 part supernatant of anti-microbial substances diluted in 4 parts of distilled water (1:4). Formulation of freeze-dry solidification of anti-microbial substances in talc was applied for seed dressing. Formulation of anti-microbial substances in powder form is a preventive measure against fungal infection particularly $S$. commune.

Finally, seed pre-treatment using anti-microbial substances enhanced seed germination, and did not inhibit seedling growth of oil palm.

\section{ACKNOWLEDGEMENT}

Part of the Ph.D. thesis of the author is financially supported by IRPA project, Malaysian Government (Vote No. 54400).

\section{REFERENCES}

Cartwright, D.K.,W.S. Chilton and D.M.Benson. 1995. Pyrrolnitrin and phenazine production by Pseudomonas cepacia, strain 5.5B, a biocontrol agent of Rhizoctonia solani. Appl. Microbiol. and Biotechnol., 43: 211-216.

Desai, S., M.S. Reddy and J.W. Kloepper. 2002. Comprehensive testing of biocontrol agents. In Biological control of crop diseases, ed. S.S. Gnanamacikam. 17: 387-420. New York: Marcel Dekker, Inc. 
Application method of antimicrobial substances - A. Dikin et al.

Dikin, A., Hermawan and Z.Zubir. 1995. Temuan Schizophyllum commune pada benih kelapa sawit asal Costa Rica.. Prosiding Kongres Nasional XIII dan Seminar Ilmiah Perhimpunan Fitopatologi Indonesia. Mataram, Indonesia. p 303-305

Dikin, A., Kamaruzaman Sijam, Zainal Abidin Mior Ahmad and Idris B Abu Seman. 2003. Biological Control of Seedborne Pathogen of Oil Palm, Schizophyllum commune Fr. with Antagonistic Bacteria. Int. J. Agric. and Biol., 5(4): 507-512.

Dikin, A., Kamaruzaman Sijam, Jugah Kadir,Idris B. Abu Seman. 2006. Effect of different carbon sources and peptones on the production of antimicrobial substances from bacteria against Scbizophyllum commune Fr. International Journal of Agriculture and Biology. Vol. 7. No. 3. 1560-8530/2005/07-3- 385-388. http://www.ijab.org

Fravel, D.R., W.J.Connick Jr and J. A. Lewis. 1998. Formulation of microorganisms to control plant disease. In Formulation of microbial biopesticides, ed. H.D. Burges. Kluwer Academic Publishers, London 5:187-202.

Turner, P.D. and R.A. Gillbanks. 2003. Oil Cultivation and management. The Incorporated Society of Planters. Kuala Lumpur. Malaysia. p.34.

Yu,J.J. and W.C. Lee. 1997. Microencapsulation of pyrrolnitrin from Pseudomonas cepacia using gluten and casein.J. Fermentation and Bioengin., 84 (5): 444-448. 